\title{
Konsepsi Merdeka Belajar Dalam Sistem Among Menurut Pandangan Ki Hajar Dewantara
}

\author{
Widya Noventari
}

Universitas Sebelas Maret Surakarta

Email: widyanoventari@staff.uns.ac.id

\begin{abstract}
ABSTRAK
Pendidan memiliki tujuan pembentukan watak dan karakter bangsa. Pembentukan watak dan karakter bangsa diperloleh dari pengembangan asek pengetahuan, sikap, dan keterampilan yang sesuai dengan pandangan hiduap suatu bangsa. Ki Hajar Dewantara sebagai tooh pendidikan di Indonesia melahirkan konsep pendidian yang disebut dengan istilah sistem among. Sistem among memiliki dua prinsip utama yakni menghargai kodrat alamiah anak dan dasar kemerdekaan serta berasaskan kekeluargaan untuk menyokong tumbuh kembang anak lahir dan batin tanpa perintah dan paksaan namun dengan tuntunan. Dua prinsip sistem among inilah yang kemudian melahirkan suatu konsepsi merdeka belajar. Konsepsi merdeka belajar dalam sistem among ini memberikan anak didik kemerdekaan sebanyak mungkin, meskipun demikian tetap harus diingat bahwa anak tidak dibenarkan apabila menggunakan itu sebebas mungkin dan melakukan segala sesuai sesuai kehendaknya dan seuka hatinya.
\end{abstract}

Kata kunci: merdeka belajar, sistem among, Ki Hajar Dewantara.

\section{PENDAHULUAN}

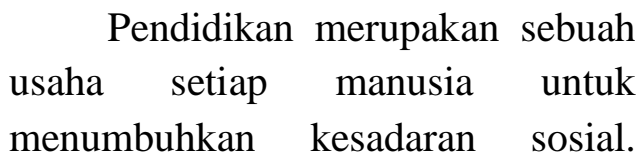
Melalui jalan pendidikan diharapkan setiap manusia memiliki ilmu pengetahuan menuju peradaban manusia berkualitas dan lebih baik. Oleh karena itu tidak heran jika setiap negara bangsa selalu menjadikan pendidikan sebagai media untuk mencerdaskan kebidupan bangsa yang akan membawa bangsa ini pada era aufklarung (pencerahan).

Merujuk pemikiran Paulo Freire (1967: 32) yang merupakan tokoh pendidikan yang anti terhadap seegala bentuk imperialism maupun ekspoitasi manusia, maka beliau menyatakan bahwa hanya melalui jalur pendidikan yang mampu mengembangkan kemampuan manusia untuk melihat tantangan dari zamanya, dari situ maka akan memunculkan dan menumbuhkan sebuah kesadaran kritis pada suatu masyarakat.

Pendidikan kritis yang digaungkan oleh freirer dewasa ini hampir menjadi wacana yang dominan diperbincangkan di dunia pendidikan di Indonesia. Sebagai seorang tokoh pendidikan yang anti 
terhadap segala bentuk penindasan terhadap manusia maka baginya hal tersebut tidak bisa di tolerir begitu saja. Sebab penindasan itu, menurutnya tidak sesuai dengan nilai kemanusaan (humanisme). Disinilah dapat kita lihat bahwa dalam penyelenggaraan pendidikan seharusnya mampu "memanusiakan manusia” (Mu'arif, 2008: 74). Hal ini sangat bertolah belakang dengan kondisi pendidikan di Indonesia dimana masih banyak terjadi kasus kekerasan di dunia pendidikan salah satunya yakni kasus perundungan (bullying). Menurut Komisi Perlindungan Anak Indonesia (KPAI) dalam kurun waktu sembilan tahun terakir ini (2011 s/d 2019) ada 37.381 pengaduan kekerasan terhadap anak, untuk bullying baik di pendidikam maupun soasial emdia, angkanya mencapai 2.473 laporan kekerasan dan trenya terus meningkat (kpai.go.id).

Fenomena kekerasan dalam dunia pendidikan ini sewajarnya tidak harus terjadi, hal ini menjadi salah satu bukti hilangnya kemampuan anak untuk berempati dan mengahgai manusia lai (nilai humanism) yang seharusnya menjadi roh jadi tujuan pendidikan itu sendiri. Bercermin dari apa yang terjadi dalam dunia pendidikan saat ini maka kita harus merefleksi kembali bagaimana bapak pendidikan Indonesia yaitu Ki Hajar Dewantara (kemudian disebut KHD) mencetuskan sebuah konsepsi dasar pendidikan dengan sebutan sistem among.

Sistem among ini merupakan strategi pendidikan yang diterapkan di Perguruan Taman Siswa yang kelak menjadi cikal bakal sistem pendidikan nasional. Sistem among merupakan sebuah cara mendidik yang mencakup 3 prinsip yakni momong, among dan ngemong (inilah yang disebut "tiga mong"). Momong dalam bahasa jawa berarti suatu hasrat dalam merawar dengan tulus dan penuh kasih sayang. Among sendiri dalam bahasa jwab juga berari memberikan contoh tentang baik buruk tanpa harus menggunkan paksaan kepada anak sehingga anak dapat tumbuh dan berkembang dalam suasana batin yang merdeka, namun tetap dengan tuntunan dan apabila melanggar suatu norma maka aka nada hukuman sesuai bagian pelanggaran terhadap norma dan disiplin yang dilakukan. Sedangkan makna kata ngemong dalam bahasa jawa berarti proses untuk mengamati, merawat,dan menjaga agar anak mampu mengembangkan dirinya, bertanggung jawab dan disiplin berdasarkan nilai-nilai yang berlaku (Raharjo, 2012: 71).

Konsepsi sistem among ini merupakan suatu pemikiran yang sangat mendasar dalam bagaimana suatu proses pendidikan itu dijalankan. Pendidikan pada dasarnya tidak harus memaksa namun bukan berarti pula membiarkan anak 
berkembang bebas tanpa arah. Konsepsi ini kemudian seakan menggali ingatan peneliti tentang dasar pendidikan yang dicetuskan oleh KHD, yang saat ini seakan kembali dihidupkan melalui pendeketan kebijakan Mentri Pendidikan dan Kebudayaan RI Nadiem Makarim yakni "Merdeka Belajar dan Kampus Merdeka (MBKM)".

Menjadi sebuah tantangan tersendiri bagi peneliti untuk kemudian menggali apakah memang benar pendekatan kebijakan MBKM ini memang terinspirasi dari pemikiran KHD? Dan bagaimana sebenarnya konsepsi merdeka belajar dalam sistem among yang di implementasikan di perguruan taman siswa? Tentunya akan sangat menarik jika kita mampu memahami konsepsi merdeka belajar dalam sistem among yang dicetuskan oleh bapak pendidikan Indonesia, maka disinilah peneliti tertarik untuk mengkaji hal tersebut.

\section{METODE PENELITIAN}

Dalam penelitian ini peneliti mengunakan metode penelitian pustaka (library research). Dalam penelitian pustaka ini memiliki tujuan untuk mengumpulkan data dan infrmasi dengan berbagai macam buku, majalah, dokumen, catatan dan kisah-kisah sejarah serta data pendukung lainya. Pada dasarnyadata yang diperoleh melalui penelitian pustaka ini dapat dijadikan landasan dasar bagi penelitian (Zed, 2008: 3).

Dalam penelitian pustaka ini sumber data yang berupa buku-buku dan litelatur yang mendukung pembahasan dalam penelitian menjadi acuan utama. Sehingga kegiatan penilitian ini dengan mengumpulkan data pustka, membaca dan mengolah data serta menghasilkan analisis dan temuan dari hasil olah data.

\section{PEMBAHASAN}

\section{Sistem Among}

Pendidikan menyadi salah satu modal besar bagi suatu bangsa untuk mencapai kualitas hidup atau peradaban yang lebih baik. Dikarenakan melalui pendidikanlah upaya untuk mengembangkan kemampuan dan kepribadian setiap individu berpusat pada proses perubahan kepribadian dan watak manusia. Oleh karenanya, KHD merintis upaya untuk mewujudkan Indonesia Merdeka melalui bidang pendidikan selain pendekatan politik. Keinginan KHD adalah mendidik angkatan muda dan jiwa kebangsaaan sebagai dasar perjuangan meningkatkan derajat hidup rakyat Indonesia.

KHD kemudia menawarkan sebuah konsep pendidikan yang disebutnya dengan istilah sistem among. Sistem among ini diyakininya mampu untuk menyokong kodrat alam peserta didik melalui 
pengembangan passion atau kemampuan alamiah yang ada dalam diri setiap individu yang pastinya berbeda satu dengan yang lainya, bukan dengan "perintah-paksaan". Namun, yang dikedepankan dalam konsepsi sistem among ini adalah bukan dengan "perintah-paksaan" tetapi dengan tutunan agar berkembang lahir dan banti anak menurut kodratnya secara subur dan selamat (Yamin, 2009: 173-174).

Sistem among yang gagas oleh KHD ini memberikan kemerdekaan lahir dan batin kepada setiap peserta didik. Peserta didik dengan sadar mampu memilih jalanya untuk kearah mana dia akan berkembang. Pencapaian perkembangan yang secara sadar, alami, dan dengan tuntunan ini juga tidak terlepas dari peran seorang pamong atau guru. Perguruan taman siswa yang didirikan oleh KHD dan menjadi pelaksana dari sistem among ini memberikan konsepsi taman atau tempat bermain anak-anak dengan menggembirakan.

Sehingga setiap anak yang berada di dalamnya merasa bahagia dan gembiran untuk menembangkan kemampuan dirinya. Konsep sekolah sebagai sebuah taman belajar bagi setiap anak atau peserta didik saat ini seakan-akan kehilangan roh nya. Karena dapat dilihat beberapa kasus tidak menyenangkan disekolah terjadi pada peserta didik kini, mulai dari tindak kekerasan baik guru ke peserta didik atau sebaliknya, bullying, dan sebuah kewajiban untuk melaksanakan pendidikan bukan sebuah kebutuhan. Disinilah sebuah pemikiran sekolah menjadi tempat yang menyeramkan bagi anak terbangun. Sehigga memamng perlu kiranya untuk mengembalikan konsepsi pemikiran KHD ini pada sistem pendidikan nasional kita.

KHD memberikan kiasan pada sistem among yang digagasnya. Sistem among ini menggambarkan seorang among sama artinya dengan seorang juru tani. Guru terhadap peserta didik/anak didiknya harus berfikir, berperasaan, dan bersikap sebagai juru tani terhadap tanamanya. Seornag yang sedang bercocok tanamn harus takluk pada kodrat dari tanamanya, janganlah tanaman diperlakukan atau ditaklukkan sesuai dengan kemauan atau kepentingan juru tani itu sendiri. Juru tan tidak bisa merubah sifat dan jenis tanaman menjadi jenis tanaman lain yang berbeda dasar sifatnya. Kuru tani menyerahkan dan mengabdikan dirinya untuk kepentingan kesuburan tanamanya semata. Oleh karena itu, sebuah keharusan bagi setiap juru tani untuk tahu dan mengerti akan ilmu dalam mengasuh tanaman, untuk dapat bercocok tanam dengan baik agar menghasilkan tanaman yang subur dan berbuah baik. Menurut KHD,juru tani tidak bida memilahmilah dari mana asal pupuk, asal alat kelengkapan atau asal ilmu pengetahuan seorang juru tani. 
Namun, juru tani harus memanfaatkan segala hal yang dapat menyuburkan tanamanya menurut kodrat alamiahnya. Disinilah guru harus memiliki karakter seperti seornag juru tani, dimana dia tidak membeda-bedakan anak didiknya, tetapu berupaya menumbuh kembangkan anak didik menjadi anak yang pintar, tidak tergantung pada bantuan orang lain, dan berjiwa merdeka (Dewantara, 1956: 358).

Kiasan sistem among yang dibuat oleh KHD dengan perumpamaan juru tani bertujuan untuk mempermudah masyaakat dan juga para pamong/guru dalam melaksanakan pendidikan yang berasaskan kekeluargaan dan menyadari kodrat alam dan kemerdekaan dalam diri setiap anak didik. Sistem among sedapat mungkin memberikan dukungan da arahan bagi pamong, orang tua, masyarakat dan peserta didik untuk memahami esensi dari sebuah pendidikan. Dimana penidikan selalu berupaya dalam menyempurnakan kehidupan anak menurut kodrat alamiahnya sendiri, agar kelah dapat menghasilkan kehidupan yang bermanfaat bagi masyarakat umum, yang kekuatan dan keahlian mereka timbul dari budi luhur yang ditanamkan sejak dini tanpa "perintah-paksaan" tetapi dengan tuntunan.

\section{Konsepsi Merdeka Belajar dalam Sistem Among}

Konsepsi merdeka belajar dalam dunia pendidikan kini mnejadi perbincangan yang hangat, gagasan "merdeka belajar" ang dicanangkan oleh mentri Pendidikan dan Kebudayaan (Mendikbud) nadiem Makarim digadang-gadang sebagai angina segar bagi pedidikan Indonesia. dilangsir oleh republika.com Kepla Biro Kerjasama dan Hubungan Masyarakat kemendikbud, Evy Mulyani memaparkan bahwa memang benar slogan "merdeka belajar" ini terinspirasi filosofi oleh KHD. Slogan ini telah melalui pembahasan dengan berbagai pihak yang ada mulai dari latar belakang keilmuan hukum, sosial, etika, dan aspek pendidikan. Menurutnya KHD mengarahkan semangat dan bagaimana cara mendidik anak menjadi seornag manusia yang merdeka batinya, merdeka pikiranya, merdeka raga/tenaganya. Karena itulah ini menjadi akar filosofi merdeka belajar yang dijalankan Kemendikbud dibawah kepemimpinan Nadiem Makarim.

Esensi merdeka belajar yang terinspirasi dari KHD ini dapat ditelusuri dari dua prinsip yang ada dlaam sistem among. Menurut Rifa'ai (2011: 108-109) sistem pendidikan pada taman siswa yang disebut sistem among mengedepankan dua prinsip sebagai berikut;

1) Kodrat Hidup Anak

Kodrat hidup anak ini melputi kodrat ilahi yakni sutau 
kemampuan yang dimiliki oleh anak sebagai anugerah dari Tuhan. Pendidikan tidak dapat memaksa dan ikut menentukan secara mutlak kodrat yang dimiliki oleh setiap anak. Kodrat anak ini terwujud sebagai bakat anak. Disinilah peran pendidikan dalam mendudukung anak untuk mengembangkan dirinya. Pendidikan baru akan turut campur tangan pabila anak memerlukan bimbingan dan tuntunan agar anak tidak menyimpang dari garis dasarnya.

2) Dasar Kemerdekaan

Dasar kemerdekaan memeberikan kesempatan seluas-luasnya pada anak untuk mengembangkan dirinya. Anak didik pada dasarnya harus diberikan kemerdekaan menggunakan cipta, rasa dan karsanya sendiri. Dasar kemerdekaan ini menginginkan agar anak menjadi ornag dewasa yang merdeka lahir dan batinya, yang disertai ras atanggung jawab.

Dua prinsip sistem among ini menjadi landasan pentingnya kemerdekaan diri setiap anak untuk menentukan jalan hidupnya di masa depan dengan mempertimbangkan bakat lamiahnya dan memebrikan kemerdekaan dalam menggunakan segala aspek kemampuanya. Sejalan dengan itu Reeve (2013: 16-17) menyebutkan baha dalam diri setiap individu memiliki irama yang dibedakan dalam tiga kekuatan besar disebut "tri sakti" yakni pikiran (cita) yang membuahkan pengetahuan pendidikan dan filsafat; rasa, yang membuahkan keindahan, keluhuran batin, seni, adat istiadat, penyesuaian sisoal, nasionalisme, keadilan dan agama, dan terakit adalah karsa (kemauan) yang menimbulkan perbuatan dan buatan manusia.

Disinilah sistem among dapat dilihat sebagai sebuah sistem atau cara mendidik anak dengan mengingat kodratnya. KHD mengugkapkan bahwa buah dari pendidikan tidak lain adalah "kematangan jiwa" yang kelat mampu mejudukan kehidupan yang tertib, baik, dan bermanfaat bagi rang lain (Warjodo, 1956: 186). Konsepsi merdeka belajar dalam sistem among ini memebrikan anak didik kemerdekaan sebanyak mungkin, meskipun demikian tetap harus diingat bahwa anak tidak dibenarkan apabila menggunakan itu sebebas mungkin dan melakukan segala sesuai sesuai kehendaknya dan seuka hatinya. Kemerdekaan yang diberikan tetap dengan batasan agar anak tetap dalam koridor yang sesuai dengan tujuan pendidikan dalam pembentukan kepribadian dan watak bangsa Indonesia yang luhur.

Sistem among yang dikemukaan oleh KHD ini merupakan sebuah warisan luhur bagi bangsa Indonesia karena ini merupakan upaya nyata dalam membentuk watak dan kepribadian anak bangsa. 
Demikian pula dalam perkembangan anak didik sangat diperlukan dorongan pamong/ guru serta peran keluarga sebagai pendidikan pertama dan utama. Peran dan dorongan pamong dan ornag tua dalam pekembangan diri anak didik ini sangat diperlukan dalam pembentukan kepribadian, kemandiri an, kemampuan bertanggung jawab pada diri dan prestasi anak didi menjadi lebih baik.

\section{SIMPULAN DAN SARAN}

\section{A. Simpulan}

Sistem among yang digagas oleh KHD dan kemudia diimplementasikan pada perguruan taman siswa merupakan wujud nyata perjuangan seorang KHD dalam upaya memujudkan Indonesia Merdeka melalui jalur pendidikan. Oleh karenya pendidikan memiliki tujuan utama dalam pembentukan watak dan kepribadian bangsa. KHD menawarkan sebuah konsep pendiidkan dengan simtem among yang menyokong kodrat alami anak, bukan dengan "perintah dan paksaan" namun dengan tuntunan agar berkembang lahir dan batinya secara subur dan selamat.

Semua itu dapat terwujud jika anak mendapatkan kebebasan secara lahir dan batin untuk mengenali kodrat alamiah dan kemerdekaan dalam cipta, karya, karsa. Melalui sistem among kemerdekaan belajar ini didukung melalui dua prinsip yakni menghargai kodrat hidup anak dan dasar kemerdekaan.

\section{B. Saran}

Gagasan KHD yang sampai saat ini cukup relevan intuk diterapkan dalam sistem pendidikan nasional seharusnya mampu menjadi cerminan kita bersama bahwa sistem pendidikan yang baik yakni sistem pendiidkan yang terlahir dari akar kebudayan masyarakaat Idonesia sendiri. Arahan dan konsep merdeka belajar oleh Kemendikbud saat ini menjadi arahan bagi para pendidik agar mampu memahami esensi pendidikan dan mempelajari sistem among KHD serta kemudia mampu mengimplementasikannya dalm proses pembelajaran baik di pendidikan formal maupun informal.

Prinsip penghargaan terhadap kodrat alami anak dan dasar kemerdekaan dalam sistem among ini menjadi prinsip utama dalam proses pembelajaran formal dan informal. Selain itu asas kekeluargaan dalam sistem among menjadi sebuah arahan untuk mendukung tumbuh kembang anak didik sesuai dengan kepribadian budaya bangsaanya. Hal ini, menjadi refleksi bagi kita semua untuk tidkak mudah goyak melirik sistem pendidikan negara lain yang belum tentu cocok dengan kepribadian bangsa sendiri. Kita boleh belajar dari sistem pendidikan manapun namun hanya sebatas untuk menambah 
cakrawala berfikir dan kemudian tetap mempertimbangkan kondisi kebudayaan masyarakat Indoensia sendiri dalam pembuatan kebijakan pendidikan agar sejalan dengan tujuan nasional yakni mencerdaskan kehidupan bangsa. 
91 Widya Noventari: konsepsi merdeka belajar dalam sistem among menurut ...

\section{DAFTAR PUSTAKA}

Dewantara, KH. (1956). "Azas-azas dan Dasar-dasar Taman-Siswa" dalam “30Tahun Taman-Siswa”. Jogjakarta: Pertjetakan Taman-Siswa.

Freire, P. (1967). Pendidikan Sebagai Praktek Pembebasan. Jakarta: Gramedia.

Garasi.Reeve, D. (2013).Golkar Sejarah yang Hilang: Akar pemikiran \&Dinamika. Jakarta: Komunitas Bambu.

Jurnal Inovasi dan Teknologi Pembelajaran <online> <http://journal2.um.ac.id/index.php/jinotep/article/view/2382/1434> diakses pada 23 Mei 2020.

Mu'arif. (2007). Liberalisasi Pedidikan: Menggadaikan Kecerdasan Kehidupan Bangsa. Yogyakarta: Pinus Book Publisher.

Rahardjo, S. (2012). Ki Hajar Dewantara: Biografi Singkat 1889-1959. Jogjakarta: Ar-Ruzzmedia.

Rifa'i, M. (2011).Sejarah Pendidikan Nasional: Dari Masa Klasik Hingga Modern. Yogyakarta: Ar-Ruzzmedia.

Tim KPAI, 2020, Sejumlah Kasus Bullying Sudah Warnai catatan Masalah anak di Awal 2020, Begini Kata Komisioner KPAI <Online> <https://www.kpai.go.id/berita/sejumlah-kasus-bullying-sudah-warnaicatatan-masalah-anak-di-awal-2020-begini-kata-komisioner-kpai> diakses pada 23 Mei 2020.

Warjodo. (1956). "Sedikit Tentang Organisasi Perguruan" dalam "30 TahunTaman-Siswa". Jogjakarta: Pertjetakan Taman-Siswa.

Widyanuratikah, Inas dan Aminah, Andi Nur, 2020, Istilah Merdeka Belajar Terinspirasi dari Ki Hajar Dewantara <online> <https://republika.co.id/berita/qdfoe3384/istilah-merdeka-belajarterinspirasi-dari-ki-hajar-dewantara> diakses pada 24 Mei 2020.

Yamin, M. (2009). Menggugat Pendidikan Indonesia: Belajar Dari Paulo Freiredan Ki Hajar Dewantara. Yogyakarta:Ar-Ruzz Media.

Zed, M. (2008). Metode Penelitian Kepustakaan. Jakarta: Yayasan Obor Indonesia 